\title{
Analysis of resistance-associated gene expression in docetaxel-resistant prostate cancer cells
}

\author{
SANGCHUL LEE $^{1^{*}}$, KWANGTAEK KIM ${ }^{2 *}$, JIN-NYOUNG HO ${ }^{1}$, \\ HYUNJIN JIN $^{1}$, SEOK-SOO BYUN ${ }^{1}$ and EUNSIK LEE ${ }^{3}$
}

\author{
${ }^{1}$ Department of Urology, Seoul National University Bundang Hospital, Seongnam 13620; ${ }^{2}$ Department of \\ Urology, Gachon University Gil Medical Center, Incheon 21565; ${ }^{3}$ Department of Urology, Seoul National \\ University College of Medicine, Seoul National University Hospital, Seoul 110-744, Republic of Korea
}

Received April 27, 2016; Accepted April 25, 2017

DOI: $10.3892 / 01.2017 .6541$

\begin{abstract}
Docetaxel-based chemotherapy is the standard treatment for metastatic castration-resistant prostate cancer (CRPC). However, a number of patients with metastatic CRPC are refractory to docetaxel or develop docetaxel resistance. The underlying molecular mechanisms of docetaxel resistance remain unclear, which is a significant burden to the management of metastatic prostate cancer. In the present study, the differential gene expression between docetaxel-sensitive (PC3) and docetaxel-resistant (PC3DR2) prostate cancer cells was identified using DNA microarrays, western blot analysis and reverse transcription-quantitative polymerase chain reaction. Of the genes implicated in cancer-associated pathways, insulin-like growth factor 1 receptor, DBF4 homolog, sterile $\alpha$ motif and leucine zipper-containing kinase AZK, Patched 1, serpin peptidase inhibitor, clade E, member 1 and breast cancer 2 (BRCA2) were $>3$-fold upregulated in PC3DR2 cells compared with PC3 cells. BRCA2 knockdown with small interfering RNA decreased the docetaxel resistance of PC3DR2 cells. These results suggest that BRCA2 serves an important role in the docetaxel resistance of prostate cancer cells. In addition, BRCA 2 modulation may be a strategy to partially reverse docetaxel resistance in prostate cancer.
\end{abstract}

\section{Introduction}

Prostate cancer, the most common non-cutaneous malignancy, is the second leading cause of cancer-associated mortality for males in the US, behind lung cancer (1). As localized prostate cancer can be cured by surgery or radiotherapy, the major public health burden comes from the metastatic stage of

Correspondence to: Professor Eunsik Lee, Department of Urology, Seoul National University College of Medicine, Seoul National University Hospital, 28 Yeongeon-dong, Jongno, Seoul 110-744, Republic of Korea

E-mail: eslee@snu.ac.kr

*Contributed equally

Key words: prostate, carcinoma, docetaxel, resistance, gene prostate cancer, for which there are currently limited curative options. A typical first-line treatment for metastatic prostate cancer is androgen deprivation therapy. However, the initial response to hormone therapy is not maintained for a long time; hormone therapy resistance, which leads to a disease state termed castrate-resistant prostate cancer (CRPC), emerges within a median time of 1.5 years (2). A previous study of patients with CRPC revealed that $\sim 67 \%$ of patients responded to long-term androgen hormone blockade; the median survival time of non-responder patients was $<1$ year (2).

Docetaxel was approved by the US Food and Drug Administration in 2004 and has been evaluated in randomized Phase III trials for patients with metastatic CRPC to overcome the limitations of hormone therapy (3). Docetaxel chemotherapy prolonged median overall survival by $\sim 3$ months when compared with mitoxantrone and prednisone, and exhibited palliative benefits for a number of patients with metastatic CRPC (3). Docetaxel exerts its effect by targeting microtubules, which consist of filamentous polymers of $\alpha$ - and $\beta$-tubulin heterodimers and are critical for cell division (4). Docetaxel binds to $\beta$-tubulin and stabilizes microtubule structures, which inhibits the mitotic spindle apparatus. Thus, docetaxel-susceptible cells exhibit mitotic arrest, leading to apoptosis (5).

Although docetaxel was the first cytotoxic therapy demonstrated to exhibit a survival benefit in patients with CRPC, the median time to prostate-specific antigen progression is limited to 6-8 months, and additional chemotherapy options at progression are required (6). Furthermore, $\sim 50 \%$ of patients with CRPC do not respond to docetaxel therapy, presenting a significant clinical problem (7). Furthermore, initial responders to docetaxel treatment ultimately develop docetaxel resistance. Proposed mechanisms for this resistance include the inhibition of drug accumulation into cancer cells, circumventing the cytotoxic effect via the upregulation of alternative growth pathways and the development of apoptosis resistance (5). However, the exact mechanism for docetaxel resistance has yet to be elucidated. De novo and acquired resistance to docetaxel chemotherapy are likely to be the main limitations to its efficacy.

A treatment regimen to overcome docetaxel resistance may be a viable alternative therapeutic strategy as there are currently a limited number of treatment options available to patients with CRPC.In our previous study, a cisplatin-resistant bladder cancer 
cell line was established to identify the genes associated with cisplatin resistance in bladder cancer (8). A docetaxel-resistant prostate cell line (PC3DR2) was subsequently established using the same method (9); resistance-associated genes in this cell line were examined in the present study through DNA microarray, western blot analysis and reverse transcription-quantitative polymerase chain reaction (RT-qPCR).

In the present study, PC3DR2 cells were identified to exhibit a 3-fold increase in the expression of insulin-like growth factor 1 receptor (IGF1R), DBF4 homolog (DBF4), sterile $\alpha$ motif and leucine zipper-containing kinase AZK (ZAK), patched 1 (PTCH1), serpin peptidase inhibitor, clade E, member 1 (SERPINE1) and breast cancer 2 (BRCA2) from cancer-associated pathways compared with a docetaxel-sensitive cell line (PC3). BRCA2 small interfering (si)RNA knockdown restored docetaxel sensitivity in PC3DR2 cells, suggesting that BRCA2 may be associated with docetaxel resistance in human prostate cancer cells.

\section{Materials and methods}

Cell lines and chemicals. PC3 CRPC cells were obtained from the American Type Culture Collection (Manassas, VA, USA) and cultured in Dulbecco's modified Eagle's medium (DMEM; Gibco; Thermo Fisher Scientific, Inc., Waltham, MA, USA) supplemented with $10 \%$ fetal bovine serum (MediaTech, Inc.; Corning Incorporated, Corning, NY, USA), $100 \mathrm{U} / \mathrm{ml}$ penicillin and $100 \mathrm{mg} / \mathrm{l}$ streptomycin (Gibco; Thermo Fisher Scientific, Inc.) with $5 \% \mathrm{CO}_{2}$ at $37^{\circ} \mathrm{C}$. A docetaxel-resistant CRPC cell line (designated PC3DR2) was generated by serial desensitization of PC3 cells as previously described $(8,9)$. Docetaxel was obtained from Sanofi-Aventis Korea Co., Ltd. (Seoul, South Korea).

Cytotoxicity assay. The cytotoxic effect of docetaxel was determined using a Cell Counting Kit-8 (CCK-8) assay (Dojindo Molecular Technologies, Inc., Rockville, MD, USA). Approximately 4,000 cells were seeded in 96-well plates with $100 \mu \mathrm{l}$ DMEM, and the cells were treated with increasing doses of docetaxel $(0,0.005,0.01,0.1,0.5,1,2.5,5,10,20$ or $50 \mu \mathrm{M}$ diluted with DMEM) for $72 \mathrm{~h}$ under the aforementioned conditions. Following incubation, $10 \mu \mathrm{l} \mathrm{CCK-8} \mathrm{solution}$ was added and the absorbance at $450 \mathrm{~nm}$ was determined $3 \mathrm{~h}$ after further incubation under the same conditions.

Apoptosis and survival-associated protein expression. Total protein was extracted from PC3DR2 cells with or without $2 \mu \mathrm{g} / \mathrm{ml}$ docetaxel treatment using radioimmunoprecipitation assay lysis buffer [containing $50 \mathrm{mM}$ tris- $\mathrm{HCl}$ (pH 8.0), $150 \mathrm{mM}$ sodium chloride, $1.0 \%$ NP-40, $0.5 \%$ sodium doxycholate, $0.1 \%$ sodium dodecyl sulfate and $1 \mathrm{mM}$ phenylmethylsulfonyl fluoride]. Protein concentrations were determined using the Pierce BCA Protein Assay kit (Thermo Fisher Scientific, Inc.). Equal amounts of protein $(20 \mu \mathrm{g})$ were separated by $8-12 \%$ SDS-PAGE and transferred onto polyvinylidene fluoride membranes (EMD Millipore, Billerica, MA, USA) blocked with Tris-buffered saline with Tween-20 containing 5\% skimmed milk for $1 \mathrm{~h}$ at room temperature.

Membranes were incubated overnight at $4^{\circ} \mathrm{C}$ with primary antibodies diluted to 1:1,000 against Akt (cat. no., \#4060), phosphorylated (p)-Akt (cat. no., \#4685), phosphoinositide 3-kinase (PI3K; cat. no. 4257), p-PI3K (cat. no. 4228), mechanistic target of rapamycin (mTOR, 2983), p-mTOR (cat. no. 2971), p70 ribosomal S6 kinase (p70S6; cat. no. 2708), p-p70S6 (cat. no. 9205), glycogen synthase kinase- $\beta$ (GSK- $\beta$, cat. no. 9315), p-GSK- $\beta$ (cat. no. 9323), p-eukaryotic translation initiation factor 4E-binding protein 1 ( $\mathrm{P}-4 \mathrm{E}-\mathrm{BP} 1$; cat. no. 2855), p-inhibitor of nuclear factor $\kappa \mathrm{B}$ kinase $\alpha$ (p-IKK $\alpha$; cat. no. 2694), cyclin A (cat. no. 4656), B1 (cat. no. 4138) and D1 (cat. no. 2978), cell division cycle 2C (CDC2C; cat. no. 9112), p-CDC2C (cat. no. 9111), retinoblastoma protein (pRb; cat. no. 9308), p21 (cat. no. 2946), caspases 3 (cat. no. 9664) and 8 (cat. no. 9496), poly (ADP-ribose) polymerase (PARP; cat. no. 9542) cellular inhibitor of apoptosis (cIAP) 1 (cat. no. 4952) and 2 (cat. no. 3130), $\beta$-actin (cat. no. 4970; all Cell Signaling Technology, Inc., Danvers, MA, USA), B-cell lymphoma 2 (Bcl-2; cat. no. sc-7382) and Bcl-2-associated agonist of cell death (Bad; cat. no. sc-8044) and X-apoptosis regulator (Bax; cat. no. sc-70405; all Santa Cruz Biotechnology, Inc., Dallas, TX, USA). Following incubation with secondary antibodies (anti-mouse, cat. no. sc-2055; dilution, 1:1,000; anti-rabbit, cat. no. sc-2004, dilution, 1:5,000, Santa Cruz Biotechnology, Inc.) for $1 \mathrm{~h}$ at room temperature, protein expression was detected using an enhanced chemiluminescence western blot substrate kit (Pierce $^{\mathrm{TM}}$ ECL Western Blotting Substrate kit; Thermo Fisher Scientific, Inc.).

Microarray analysis. Total RNA was extracted from PC3 and PC3DR2 cells using the RNeasy ${ }^{\circledR}$ Protect Mini kit (Qiagen, Inc., Valencia, CA, USA) according to the manufacturer's protocol. RNA samples with high RNA integrity numbers (RIN>9.0). Agilent 2100 Bioanalyzer System and RNA kits developed by Agilent Technologies (Santa Clara, CA, USA) with A260/280 ratios of 1.8-2.1 were used for cDNA synthesis. Amplification cycles of RNA to cDNA and cDNA to biotin-labeled RNA were performed with the GeneChip IVT Express kit (Affymetrix; Thermo Fisher Scientific, Inc.). RNA was hybridized to a GeneChip Human Genome HG-U133 Plus 2.0 array (Applied Biosystems; Thermo Fisher Scientific, Inc.); all microarray steps were performed according to the manufacturer's protocol. The MAS5 algorithm in GenPlex software ver. 3.0 (Istech Corp., Seoul, Korea) was used for analyzing the CEL file data. The Affymetrix Microarray Suite, MicroDB, and Data Mining Tool software v. 5.0 (Thermo Fisher Scientific, Inc.) were used to annotate 54,120 probe sets with 17,084 genes from the UniGene database. Following global scaling regression normalization, the data was log transformed to base 2. Gene expression levels in PC3 and PC3DR2 cells compared using the $n$-fold method. Differentially expressed gene clusters were analyzed using GeneCluster 1.0 (MIT, Cambridge, MA, USA). GenMAPP was used to analyze the functional pathways associated with differentially expressed genes. (http://www. genmapp.org).

$R T-q P C R$. Total RNA was extracted from PC3 and PC3DR 2 cells using the RNeasy ${ }^{\circledR}$ Protect Mini kit as aforementioned. cDNA was produced from $1 \mu \mathrm{g}$ total RNA using oligo(dT) primers and Omniscript reverse transcriptase enzyme (both Qiagen, Inc.) according to the manufacturer's protocol. qPCR was performed with the cDNA produced from 10 ng RNA with the FastStart Universal SYBR Green Master mix (Roche Diagnostics, 
Table I. Primer sequences for reverse transcription-quantitative polymerase chain reaction.

\begin{tabular}{|c|c|c|c|}
\hline Gene symbol & Gene name & Direction & Primer sequence $\left(5^{\prime}-3^{\prime}\right)$ \\
\hline \multirow[t]{2}{*}{ IGF1R } & \multirow[t]{2}{*}{ Insulin-like growth factor 1 receptor } & Forward & GTCCTCCTTGATGGTGGAAT \\
\hline & & Reverse & GTTCAAAACCTTGCCCACAT \\
\hline \multirow[t]{2}{*}{ BRCA2 } & \multirow[t]{2}{*}{ Breast cancer 2} & Forward & ATGCAAATGCATACCCACAA \\
\hline & & Reverse & AGGTGGCCCTACCTCAAAAT \\
\hline \multirow[t]{2}{*}{ DBF4 } & \multirow[t]{2}{*}{ DBF4 homolog } & Forward & GGGTAACTGGAAGCCATGAA \\
\hline & & Reverse & CATGAGCCACAGGAGAGTCA \\
\hline \multirow[t]{2}{*}{ ZAK } & \multirow[t]{2}{*}{ Sterile $\alpha$ motif and leucine zipper-containing kinase AZK } & Forward & GCTGCCTTCCTTTGAGATTG \\
\hline & & Reverse & CCGCTTCCCTGTAATGTTGT \\
\hline \multirow[t]{2}{*}{ PTCH1 } & \multirow[t]{2}{*}{ Patched 1} & Forward & AGGGATTCCAAGGTGGAAGT \\
\hline & & Reverse & TGGCCTCTTTGCTTCAGATT \\
\hline \multirow[t]{2}{*}{ SERPINE1 } & \multirow[t]{2}{*}{ Serpin peptidase inhibitor, clade E, member 1} & Forward & TATCCTTGCCCTTGAGTGCT \\
\hline & & Reverse & AGTGGCTGGACTTCCTGAGA \\
\hline \multirow[t]{2}{*}{ CDKN2C } & \multirow[t]{2}{*}{ Cyclin-dependent kinase inhibitor $2 \mathrm{C}$} & Forward & ACGTCAATGCACAAAATGGA \\
\hline & & Reverse & TCATGAATGACAGCCAAACC \\
\hline \multirow[t]{2}{*}{ CDC6 } & \multirow[t]{2}{*}{ Cell division cycle 6 homolog } & Forward & TCTGATTCCCAAGAGGGTTG \\
\hline & & Reverse & TTCTGCTGAAGAGGGAAGGA \\
\hline \multirow[t]{2}{*}{$\mathrm{CDC} 25 \mathrm{C}$} & \multirow[t]{2}{*}{ Cell division cycle 25 homolog $\mathrm{C}$} & Forward & TGGGGAGATAACTGCCACTC \\
\hline & & Reverse & AAGCTGTGCTGGGCTACATT \\
\hline \multirow[t]{2}{*}{ CCNE2 } & \multirow[t]{2}{*}{ Cyclin E2 } & Forward & CCGAAGAGCACTGAAAAACC \\
\hline & & Reverse & GAATTGGCTAGGGCAATCAA \\
\hline \multirow[t]{2}{*}{ WNT3 } & \multirow[t]{2}{*}{ Wingless-type MMTV integration site family, member 3} & Forward & CGCCTCGGAGATGGTAGTAG \\
\hline & & Reverse & AAAGTTGGGGGAGTTCTCGT \\
\hline \multirow[t]{2}{*}{ FLI1 } & \multirow[t]{2}{*}{ Friend leukemia virus integration 1} & Forward & TGCACTCAGCTGACCACTCT \\
\hline & & Reverse & TTTCCAAGTTCTGGGACCAC \\
\hline \multirow[t]{2}{*}{ CUL2 } & \multirow[t]{2}{*}{ Cullin 2} & Forward & GCATAGGACTGCATTCAGCA \\
\hline & & Reverse & GCGATGTCTGTGGAGTAGCA \\
\hline
\end{tabular}

Indianapolis, IN, USA) using a 7500 Real-Time PCR system (Applied Biosystems; Thermo Fisher Scientific, Inc.). The sample was incubated at $95^{\circ} \mathrm{C}$ for $15 \mathrm{~min}$, followed by 40 cycles of $95^{\circ} \mathrm{C}$ for $15 \mathrm{sec}$, annealing at $58^{\circ} \mathrm{C}$ for $30 \mathrm{sec}$ and extension at $72^{\circ} \mathrm{C}$ for $30 \mathrm{sec}$. GAPDH was used as the reference gene. Fold change in gene expression was calculated following the $2^{-\Delta \Delta \mathrm{Cq}}$ method (10). Primer sequences are presented in Table I.

siRNA preparation and transfection. si-BRCA2 specific for long-form BRCA2 was synthesized by Invitrogen; Thermo Fisher Scientific, Inc., according to published sequences $(11,12)$. Scrambled siRNA (si-SCR) was obtained from Dharmacon (cat. no., \#D-001210-01; GE Healthcare, Chicago, IL, USA). For transfection, $10 \mathrm{nM}$ siRNA was mixed with DharmaFECT $^{\circledR} 1$ transfection reagent (Dharmacon; GE Healthcare) and used according to the manufacturer's protocol.

Statistical analysis. Unless indicated otherwise, datasets consist of $>3$ replicates. Data are presented as the mean \pm standard deviation. Statistical significance between groups was determined using an unpaired Student's t-test. $\mathrm{P}<0.05$ was considered to indicate a statistically significant difference.

\section{Results}

Establishment of a docetaxel-resistant prostate cancer cell line (PC3DR2). A docetaxel-resistant prostate cancer cell line

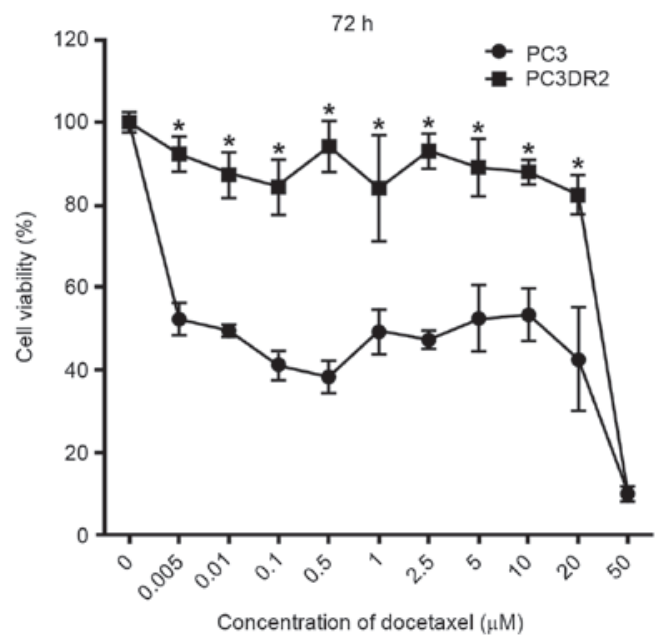

Figure 1. Cell Counting Kit-8 assays following $72 \mathrm{~h}$ of treatment with docetaxel in PC3 and PC3DR2 prostate cancer cells. Results represent the mean \pm standard deviation $(n=3)$. ${ }^{*} \mathrm{P}<0.05$ compared with $\mathrm{PC} 3$ cells by t-test.

(PC3DR2) was generated by serial desensitization. To confirm the docetaxel resistance, PC3 and PC3DR2 cells were exposed to increasing doses of docetaxel $(0,0.005,0.01,0.1,0.5,1$, $2.5,5,10,20$ or $50 \mu \mathrm{M}$ ) for $72 \mathrm{~h}$. The extent of the cytotoxic effect of docetaxel was determined using a CCK-8 assay. As presented in Fig. 1, docetaxel decreased the viability of PC3 
Table II. Number of upregulated and downregulated genes and signaling pathways in PC3DR2 cells compared with PC3 cells.

\begin{tabular}{llrc}
\hline $\begin{array}{l}\text { Fold change } \\
\text { cut-off }\end{array}$ & Regulation & Genes & $\begin{array}{c}\text { Significant } \\
\text { pathways }\end{array}$ \\
\hline 2 & Up & 1,227 & 471 \\
& Down & 1,190 & 362 \\
3 & Up & 392 & 162 \\
& Down & 243 & 67 \\
\hline
\end{tabular}

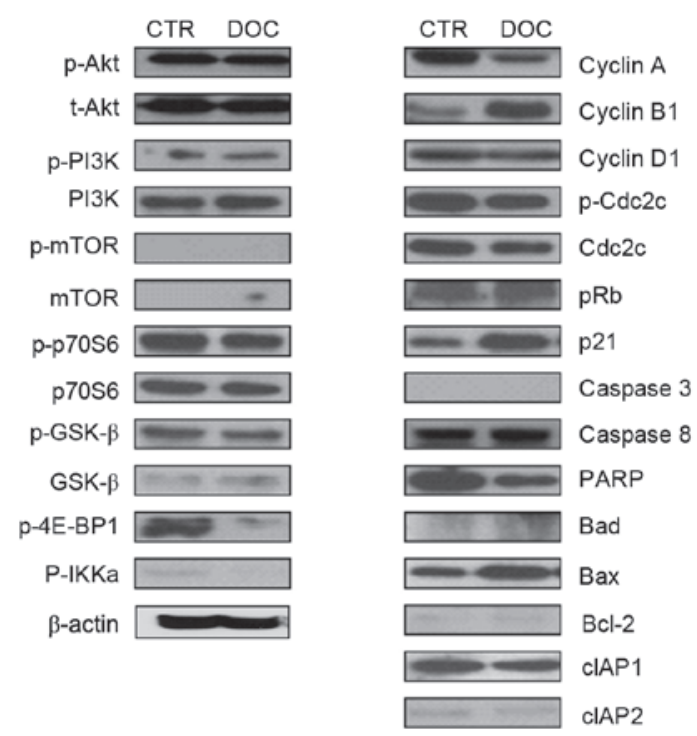

Figure 2. Protein expression analysis with western blotting in PC3DR2 prostate cancer cells. CTR, untreated PC3DR2 cells; DOC, docetaxel-treated PC3DR2 cells; p, phosphorylated; t-, total; PI3K, phosphoinositide 3-kinase; mTOR, mechanistic target of rapamycin; p70S6, p70 ribosomal S6 kinase GSK- $\beta$, glycogen synthase kinase- $\beta$; 4E-BP1, eukaryotic translation initiation factor $4 \mathrm{E}$-binding protein 1 ; IKKa, inhibitor of nuclear factor- $\mathrm{\kappa B}$ kinase $\alpha$; Cdc2C, cell division cycle $2 \mathrm{C}$; $\mathrm{pRb}$, retinoblastoma protein; PARP, poly (ADP-ribose) polymerase; Bcl-2, B-cell lymphoma 2; Bad, Bcl-2-associated agonist of cell death; Bax, Bcl-2-associated $\mathrm{X}$-apoptosis regulator; cIAP, cellular inhibitor of apoptosis.

cells in dose-dependent manner at $72 \mathrm{~h}$; a concentration of $0.005 \mu \mathrm{M}$ docetaxel was sufficient to suppress proliferation of PC 3 cells by $52 \%$ at $72 \mathrm{~h}$. However, PC3DR 2 cells were significantly more resistant to all concentrations of docetaxel $\leq 20 \mu \mathrm{M}$ at $72 \mathrm{~h}(\mathrm{P}<0.05)$; the $20 \mu \mathrm{M}$ PC3DR2 group exhibited $\sim 80 \%$ viability, whereas the $20 \mu \mathrm{M}$ PC3 group exhibited $\sim 50 \%$ viability. Thus, it was established that PC3DR2 cells exhibited significant resistance to docetaxel doses $\leq 20 \mu \mathrm{M}$.

Effect of docetaxel resistance in PC3DR2 cells on cell cycle, survival and apoptosis signaling pathways. To investigate the characteristics of signaling molecules and response of PC3DR2 cells to docetaxel treatment, alterations to proteins in cell cycle-, survival-, and apoptosis-associated signaling pathways in PC3DR2 cells were examined following docetaxel treatment. Levels of cell survival-(Akt, PI3K, p70S6, mTOR and GSK $\beta$ ), cell cycle-(cyclin D1, p-CDC2C and pRb) and apoptosis-(caspases 3 and 8, Bad, Bcl-2, cIAP1 and 2) associated signaling molecules were not altered in PC3DR 2 cells following docetaxel treatment. Notably, 4E-BP1, a repressor of mRNA translation, was inactivated by docetaxel treatment in PC3DR2. However, expression of some cell cycle-associated molecules (cyclin A, cyclin B1 and p21) and Bax was changed following docetaxel treatment (Fig. 2).

DNA microarray analysis of PC3DR2 cells. A total of 17,084 genes were analyzed; 1,227 genes were 2-fold upregulated, whereas 1,190 genes were 2-fold downregulated between PC3 and PC3DR2 cells. A total of 392 genes were 3-fold upregulated, whereas 243 genes were 3 -fold downregulated (Table II). In addition, to identify docetaxel resistance-associated genes, 13 differentially expressed genes associated with biological processes possibly associated with docetaxel resistance were identified, including DBF4, cyclin-dependent kinase inhibitor $2 \mathrm{C}$, cell division cycle 6 homolog, cell division cycle 25 homolog C, ZAK, SERPINE1, cyclin E2 (CCNE2), wingless-type MMTV integration site family, member 3, PTCH1, IGF1R, cullin 2, BRCA2 and Friend leukemia virus integration 1 (FLI1; Table III).v

Validation using RT-qPCR of candidate genes in docetaxel resistance. The results of the microarray analysis for the previously named genes was validated using RT-qPCR (Figs. 3-5, Table III). Of the 13 genes, those verified using RT-qPCR included DBF4, ZAK, SERPINE1, PTCH1, IGF1R and BRCA2. IGF1R, PTCH1 and BRCA2 are associated with pathways in cancer. DBF4 is associated with cell cycle. ZAK is associated with the mitogen-activated protein kinase (MAPK) signaling pathway, SERPINE1 and CCNE2 are associated with the p53 signaling pathway. We hypothesized that these genes may be associated with docetaxel resistance in PC3DR2 cells.

BRCA2 siRNA knockdown abolishes docetaxel resistance in PC3DR2 cells. Following the confirmation of the upregulation of DBF4, ZAK, SERPINE1, PTCH1, IGF1R and BRCA2 gene expression in PC3DR2 cells, the genes were investigated for their direct involvement in docetaxel resistance using an siRNA system. siRNA for each gene was transfected into PC3DR2 cells and the cell viability was determined using a CCK-8 assay following docetaxel treatment. si-BRCA2 was confirmed by RT-qPCR and western blotting to decrease the relative level of BRCA2 protein in PC3DR2 cells, whereas scrambled siRNA did not significantly affect the level of BRCA2 expression (Fig. 6A and B). The transfection of siRNA against DBF4, ZAK, SERPINE1, PTCH1 and IGF1R did not affect the docetaxel resistance of PC3DR2 cells (data not shown), whereas si-BRCA2 transfection significantly reduced docetaxel resistance at 48 and $72 \mathrm{~h}$ (Fig. 6C and D), suggesting that BRCA2 overexpression may be associated with docetaxel resistance in prostate cancer cells.

\section{Discussion}

Although docetaxel represents the most effective chemotherapeutic agent for patients with CRPC, once drug resistance develops, there are limited effective therapeutic strategy options for advanced CRPC. Thus, investigating the resistance mechanism of prostate cancer cells against docetaxel is of marked 
Table III. Genes associated with cell cycle and cancer signaling pathways that were differentially expressed in PC3DR2 cells relative to PC3 cells, as determined by DNA microarray and RT-qPCR analyses.

Fold-change in PC3DR2 cells

\begin{tabular}{llcc} 
& \multicolumn{1}{c}{ Pathway } & Microarray & RT-qPCR $^{\mathrm{b}}$ \\
\cline { 3 - 4 } DBF4 & & 24.9 & $5.2^{\mathrm{c}}$ \\
CDKN2C & Cell cycle & 3.8 & 31.2 \\
CDC6 & Cell cycle & 3.4 & 1.2 \\
CDC25C & Cell cycle & 3.2 & 0.7 \\
ZAK & Cell cycle & 4.6 & $6.2^{\mathrm{c}}$ \\
SERPINE1 & MAPK signaling pathway & 3.7 & $3.4^{\mathrm{c}}$ \\
CCNE2 & p53 signaling pathway & 3.7 & $1.4^{\mathrm{d}}$ \\
WNT3 & p53 signaling pathway & 3.3 & 1.4 \\
PTCH1 & Pathways in cancer & 3.6 & $3.2^{\mathrm{c}}$ \\
IGF1R & Pathways in cancer & 4.4 & $3.1^{\mathrm{c}}$ \\
CUL2 & Pathways in cancer & 4.6 & 1.5 \\
BRCA2 & Pathways in cancer & 3.2 & $3^{\mathrm{e}}$ \\
FLI1 & Pathways in cancer & 9.0 & $1.4^{\mathrm{e}}$ \\
\hline
\end{tabular}

${ }^{\mathrm{a}} \mathrm{Gene}$ names are defined in Table I. ${ }^{\mathrm{b}}$ Relative to GADPH. ${ }^{\mathrm{c}} \mathrm{P}<0.001,{ }^{\mathrm{d}} \mathrm{P}<0.01$, ${ }^{\mathrm{e}} \mathrm{P}<0.05$ compared with PC3 cells, Student's t-test. RT-qPCR, reverse transcription-quantitative polymerase chain reaction; MAPK, mitogen-activated protein kinase.
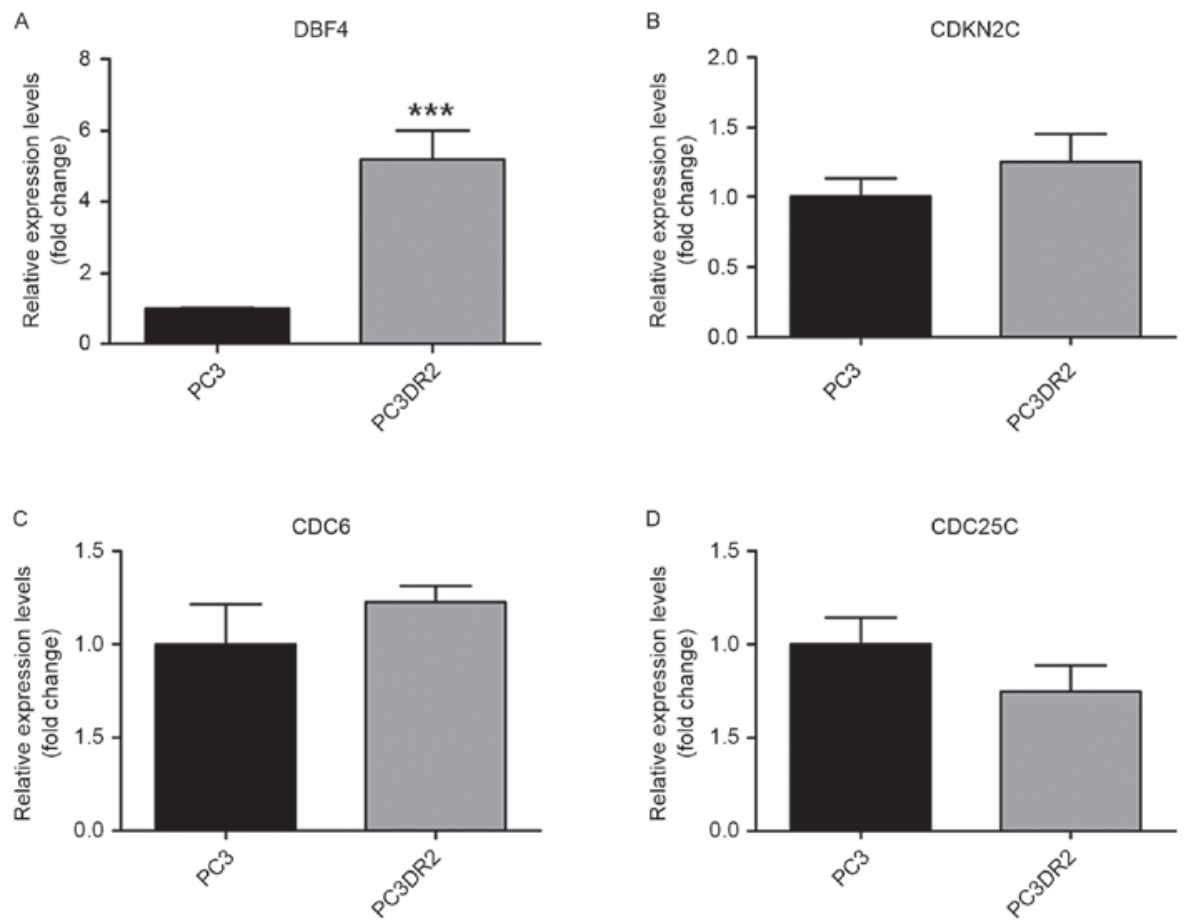

Figure 3. Cell cycle-associated gene expression analysis using qPCR in PC3 and PC3DR2 prostate cancer cells. (A) DBF4, (B) CDKN2C, (C) CDC6 and (D) $\mathrm{CDC} 25 \mathrm{C}$. The qPCR data are presented as relative values normalized to those of the internal control (GAPDH). Results represent the mean \pm standard deviation $(\mathrm{n}=3){ }^{* * *} \mathrm{P}<0.001$ compared with $\mathrm{PC} 3$ cells by t-test.

urgency. In our previous study, human docetaxel-resistance prostate cancer cell line (PC3DR2) from docetaxel-sensitive prostate cancer cell line (PC3) were generated by serial desensitization (9); in the present study, differential gene expression between PC 3 and PC3DR 2 cells were compared with a DNA microarray. O'Neill et al (13) also manipulated docetaxel-resistant prostate cancer cell lines and suggested that multiple mechanisms contribute to docetaxel resistance in partial agreement with our results, although this study focused on the nuclear factor- $\kappa \mathrm{B}$ pathway, indicating that multiple mechanisms may be involved in docetaxel resistance. In the present study, it was confirmed using western blotting analysis that the expression of a number of molecules, including those associated with the cell cycle, survival and apoptosis, were 

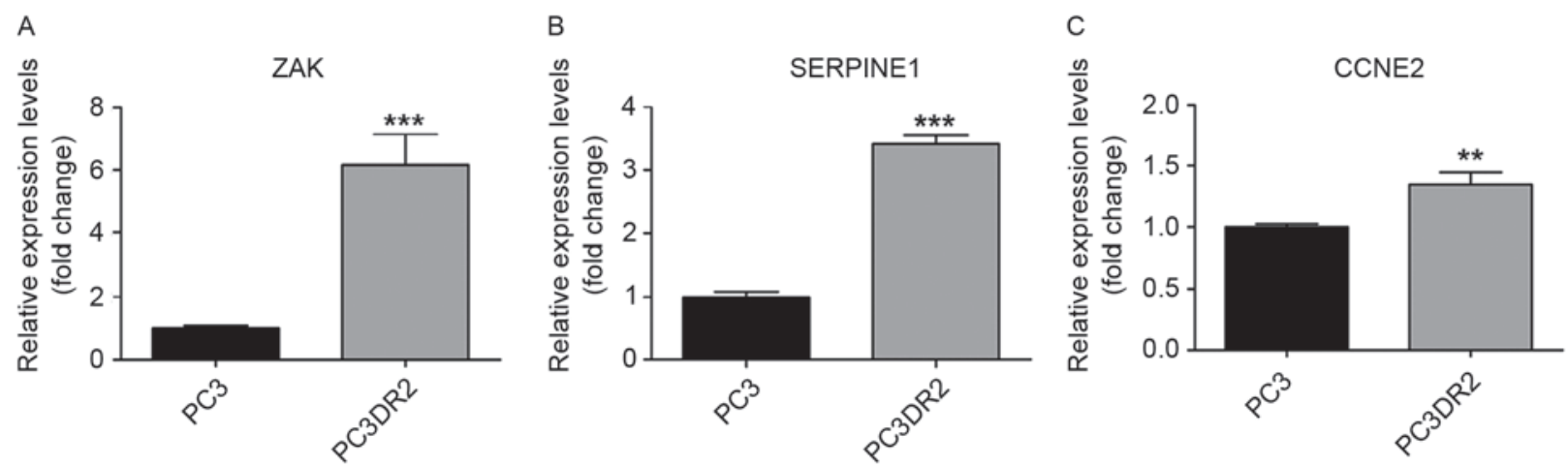

Figure 4. Signaling pathway-associated gene expression analysis using qPCR in PC3 and PC3DR2 prostate cancer cells. (A) ZAK, (B) SERPINE1 and (C) CCNE2. The qPCR data are presented as relative values normalized to those of the internal control (GAPDH). Results represent the mean \pm standard deviation $(\mathrm{n}=3) .{ }^{* *} \mathrm{P}<0.005$ and $^{* * * *} \mathrm{P}<0.001$ compared with $\mathrm{PC} 3$ cells by $\mathrm{t}$-test.
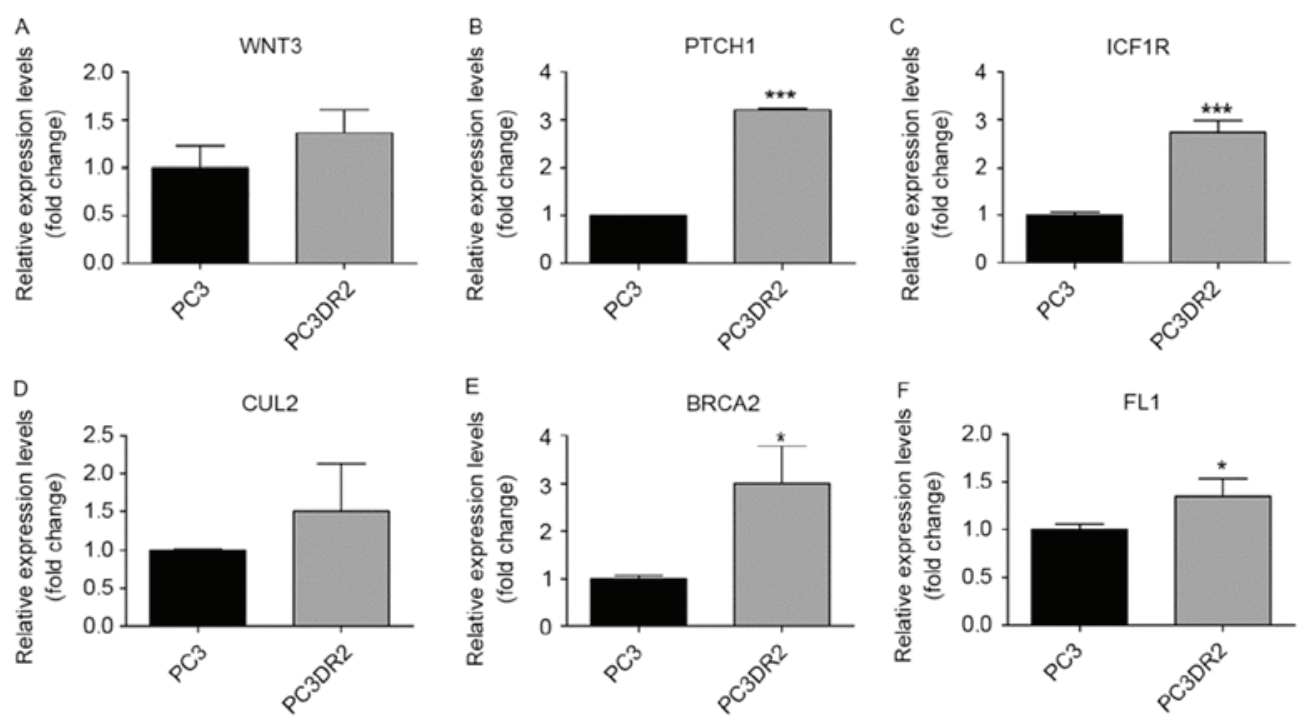

Figure 5. Cancer-associated pathway gene expression analysis by qPCR in PC3 and PC3DR2 prostate cancer cells. (A) WNT3, (B) PTCH1, (C) IGF1R, (D) CUL2, (E) BRCA2 and (F) FLI1. qPCR data are presented as relative values normalized to those of the internal control (GAPDH). Results represent the mean \pm standard deviation $(\mathrm{n}=3)$. ${ }^{*} \mathrm{P}<0.05$ and ${ }^{* * *} \mathrm{P}<0.001$ compared with $\mathrm{PC} 3$ cells by $\mathrm{t}$-test.

unchanged in PC3DR2 cells subsequent to docetaxel treatment. Using microarray analysis confirmed by RT-qPCR, six overexpressed genes (IGF1R, DBF4, ZAK, PTCH1, SERPINE and BRCA2) associated with cancer signaling pathways were identified in PC3DR2 cells, exhibiting a $>3$-fold increase compared with PC3 cells in the RT-qPCR data. To confirm the association between the overexpression of these genes and docetaxel resistance, an siRNA against each gene was transfected into PC3DR2 cells. BRCA2 knockdown abolished the docetaxel resistance in PC3DR2 cells. These results suggest the novel hypothesis that BRCA2 overexpression may be involved in docetaxel resistance.

Docetaxel stabilizes tubulin subunits in microtubules, leading to apoptosis (5). In addition, it has been demonstrated that docetaxel leads to an antitumor effect by inducing the phosphorylation of Bcl-2 (14). Suggested docetaxel resistance mechanisms include: i) Overexpression of the p-glycoprotein drug efflux pump; ii) mutation of the drug-binding site; iii) Expression of another tubulin isoform; iv) Activation of a growth factor-associated pathway; and v) Use of an alternative metabolic pathway $(5,15)$. In the present study, BRCA2 overexpression was identified as an additional possible mechanism for docetaxel resistance in PC3DR2 cells.

BRCA1 and 2 are well-known breast cancer susceptibility genes considered to be classical tumor-suppressor genes, since the loss of both alleles is required to promote carcinogenesis $(11,12,16,17)$. A recent study demonstrated that the 12 -year prostate cancer-specific survival rate was $94.3 \%$ for patients without and $61.8 \%$ for patients with a BRCA2 mutation, suggesting that the survival time for patients with a BRCA2 mutation is markedly below the average for prostate cancer (18). Mutations of BRCA genes increase the risk of prostate cancer and are associated with disease characteristics and therapeutic outcomes (19). It has been demonstrated that the functional loss of BRCA2 affects the focal development of prostate cancer (20) and the potential for the disease to spread through upregulation of matrix metalloproteinase-9 (21). Conversely, the decreased expression of BRCA2 mRNA predicts a favorable response to docetaxel in breast cancer (22). The results of the present study revealed that BRCA2 knockdown abolished 
A

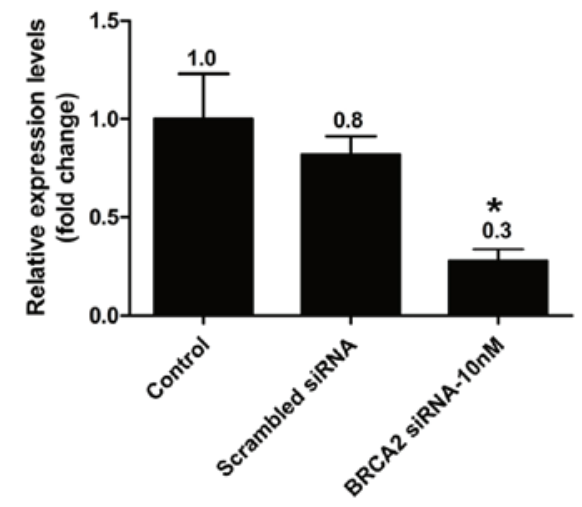

C

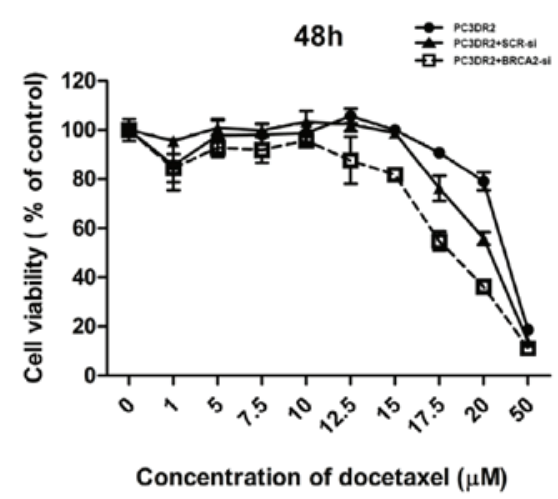

B

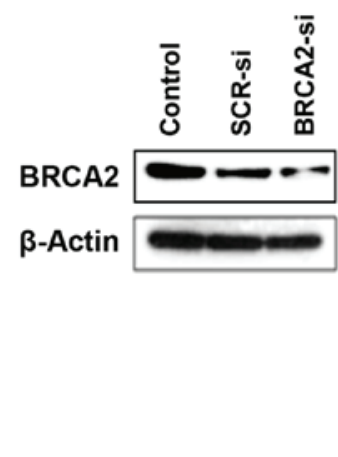

D

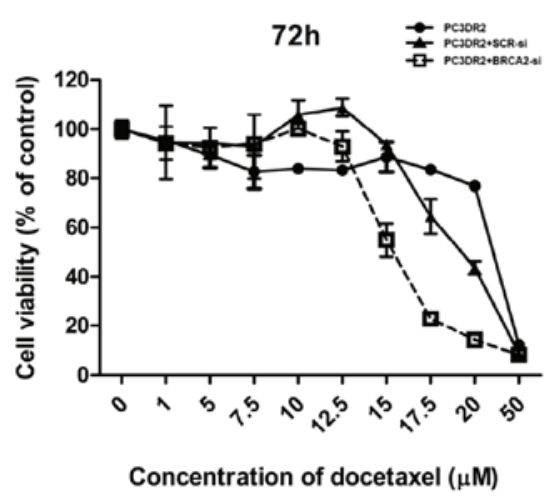

Figure 6. BRCA2 knockdown with siRNA abolished docetaxel resistance in PC3DR2 cells. BRCA2 expression in prostate cancer cells transfected with BRCA2 siRNA was demonstrated to be decreased using (A) qPCR and (B) western blot analysis. The qPCR data are presented as relative values normalized to those of the internal control (GAPDH). The cell viability of PC3DR2 cells transfected with BRCA2 siRNA for (C) 48 and (D) $72 \mathrm{~h}$ was then assessed. Results represent the mean \pm standard deviation $(\mathrm{n}=3)$. ${ }^{*} \mathrm{P}<0.05$ compared with PC3DR2 cells by t-test. BRCA2, breast cancer 2 ; siRNA, small interfering RNA; qPCR, quantitative polymerase chain reaction.

docetaxel resistance in PC3DR2 cells. Collectively, these results may appear to be conflicting; however, this effect is expected when considering that the major anticancer mechanism for docetaxel is to stabilize microtubules during mitosis to induce cell cycle arrest at G2-M phase, leading to apoptosis (5). BRCA proteins are also involved in the mitotic spindle assembly process. The normal DNA repair functions of BRCA1 and BRCA2 serve a critical function in cell cycle processes during $\mathrm{G} 2-\mathrm{M}$ phase. When BRCA2 expression is low, malfunction of the DNA repair system may retard the function of the mitotic spindle to slow or arrest the G2-M process (23). Thus, it can be speculated that tumors with low BRCA expression may be more sensitive to docetaxel treatment, indicating that docetaxel may exert a greater effect on prostate cancer cells where the function of mitotic spindles is already partially retarded due to low BRCA 2 expression, in accordance the results of the present study.

Tumor suppressor genes may regulate the sensitivity of cancer cells to chemotherapy (24). Previous studies have demonstrated that decreased BRCA1 expression following siRNA transfection may increase cell sensitivity to platinum compounds and topoisomerase inhibitors (25-27). Clinical studies also indicated that BRCA1 may be a suitable biomarker for the clinical prognosis of ovarian, lung and breast cancer treatment after DNA-damage-based targeted therapy, as reviewed by Stordal and Davey (28). An in vitro and in vivo study demonstrated that low BRCA1 expression, potentially leading to defects in the DNA damage repair mechanism, was associated with the high sensitivity to DNA-damaging drugs including cisplatin and PARP inhibitors (29). Preclinical and clinical studies have revealed that the loss of BRCA1 may also result in resistance to other types of chemotherapeutic agent, including the anti-microtubule agents paclitaxel and docetaxel, and molecularly targeted agents $(30,31)$. Therefore, BRCA1 expression affects chemosensitivity differently depending on the type of agent.

However, in the present study, BRCA1 was not identified to be significantly altered in PC3DR2 cells. This is noteworthy, as BRCA1 and BRCA2 are breast cancer-susceptibility genes that have been identified through linkage analysis of families susceptible to breast cancer $(16,17)$. However, it has also been reported that sporadic breast cancer may exhibit decreased BRCA1 mRNA levels, whereas BRCA2 mRNA levels were variable, compared with normal breast tissue (32-34). These results may be caused by the hypermethylation of BRCA1 promoter, which explains the downregulation in sporadic breast cancer, whereas the promoter for BRCA2 is not hypermethylated (34). BRCA2 may have different operating system 
from BRCA1 and it may be possible for only BRCA2 to be involved in docetaxel resistance.

In conclusion, the results of the present study suggest the novel hypothesis that BRCA2 may be associated with docetaxel resistance in human prostate cancer cells. To clarify this suggestion, further study with an in vivo model is required.

\section{Acknowledgements}

The present study was supported by the Basic Science Research Program through the National Research Foundation of Korea, funded by the Ministry of Education (grant no. NRF-2014R1A1A2059537), and the Seoul National University Bundang Hospital Research Fund (grant no. 02-2014-020).

\section{References}

1. Siegel RL, Miller KD and Jemal A: Cancer statistics, 2015. CA Cancer J Clin 65: 5-29, 2015.

2. Sella A, Yarom N, Zisman A and Kovel S: Paclitaxel, estramustine and carboplatin combination chemotherapy after initial docetaxel-based chemotherapy in castration-resistant prostate cancer. Oncology 76: 442-446, 2009.

3. Berthold DR, Pond GR, Soban F, de Wit R, Eisenberger M and Tannock IF: Docetaxel plus prednisone or mitoxantrone plus prednisone for advanced prostate cancer: Updated survival in the TAX 327 study. J Clin Oncol 26: 242-245, 2008.

4. Cortes JE and Pazdur R: Docetaxel. J Clin Oncol 13: 2643-2655, 1995.

5. Hwang C: Overcoming docetaxel resistance in prostate cancer: A perspective review. Ther Adv Med Oncol 4: 329-340, 2012.

6. Petrylak DP: New paradigms for advanced prostate cancer. Rev Urol 9 (Suppl 2): S3-S12, 2007.

7. Petrylak DP, Tangen CM, Hussain MH, Lara PN Jr, Jones JA, Taplin ME, Burch PA, Berry D, Moinpour C, Kohli M, et al: Docetaxel and estramustine compared with mitoxantrone and prednisone for advanced refractory prostate cancer. N Engl J Med 351: 1513-1520, 2004

8. Lee S, Yoon CY, Byun SS, Lee E and Lee SE: The role of c-FLIP in cisplatin resistance of human bladder cancer cells. J Urol 189: 2327-2334, 2013

9. Park HS, Hong SK, Oh MM, Yoon CY, Jeong SJ, Byun SS, Cheon J, Lee SE and Moon du G: Synergistic antitumor effect of NVP-BEZ235 and sunitinib on docetaxel-resistant human castration-resistant prostate cancer cells. Anticancer Res 34: 3457-3468, 2014.

10. Livak KJ and Schmittgen TD: Analysis of relative gene expression data using real-time quantitative PCR and the 2(-Delta Delta C(T)) method. Methods 25: 402-408, 2001.

11. Merajver SD, Frank TS, Xu J, Pham TM, Calzone KA, Bennett-Baker P, Chamberlain J, Boyd J, Garber JE, Collins FS, et al: Germline BRCA1 mutations and loss of the wild-type allele in tumors from families with early onset breast and ovarian cancer. Clin Cancer Res 1: 539-544, 1995.

12. Gudmundsson J, Johannesdottir G, Bergthorsson JT, Arason A, Ingvarsson S, Egilsson V and Barkardottir RB: Different tumor types from BRCA2 carriers show wild-type chromosome deletions on 13q12-q13. Cancer Res 55: 4830-4832, 1995.

13. O'Neill AJ, Prencipe M, Dowling C, Fan Y, Mulrane L, Gallagher WM, O'Connor D, O'Connor R, Devery A, Corcoran C, et al: Characterisation and manipulation of docetaxel resistant prostate cancer cell lines. Mol Cancer 10: 126, 2011.

14. Rangel C, Niell H, Miller A and Cox C: Taxol and taxotere in bladder cancer: In vitro activity and urine stability. Cancer Chemother Pharmacol 33: 460-464, 1994.

15. Gottesman MM, Fojo T and Bates SE: Multidrug resistance in cancer: Role of ATP-dependent transporters. Nat Rev Cancer 2 48-58, 2002.

16. Miki Y, Swensen J, Shattuck-Eidens D, Futreal PA, Harshman K, Tavtigian S, Liu Q, Cochran C, Bennett LM, Ding W, et al: A strong candidate for the breast and ovarian cancer susceptibility gene BRCA1. Science 266: 66-71, 1994.
17. Wooster R, Neuhausen SL, Mangion J, Quirk Y, Ford D, Collins N, Nguyen K, Seal S, Tran T, Averill D, et al: Localization of a breast cancer susceptibility gene, BRCA2, to chromosome 13q12-13. Science 265: 2088-2090, 1994.

18. Akbari MR, Wallis CJ, Toi A, Trachtenberg J, Sun P, Narod SA and Nam RK: The impact of a BRCA2 mutation on mortality from screen-detected prostate cancer. Br J Cancer 111: $1238-1240,2014$

19. Alanee SR, Glogowski EA, Schrader KA, Eastham JA and Offit K: Clinical features and management of BRCA1 and BRCA2-associated prostate cancer. Front Biosci (Elite Ed) 6: 15-30, 2014.

20. Francis JC, McCarthy A, Thomsen MK, Ashworth A and Swain A: Brca2 and Trp53 deficiency cooperate in the progression of mouse prostate tumourigenesis. PLoS Genet 6: e1000995, 2010.

21. Moro L, Arbini AA, Yao JL, di Sant'Agnese PA, Marra E and Greco M: Loss of BRCA2 promotes prostate cancer cell invasion through up-regulation of matrix metalloproteinase-9. Cancer Sci 99: 553-563, 2008

22. Egawa C, Miyoshi Y, Takamura Y, Taguchi T, Tamaki Y and Noguchi S: Decreased expression of BRCA2 mRNA predicts favorable response to docetaxel in breast cancer. Int J Cancer 95: 255-259, 2001

23. Mullan PB, Quinn JE, Gilmore PM, McWilliams S, Andrews H, Gervin C, McCabe N, McKenna S, White P, Song YH, et al: BRCA1 and GADD45 mediated G2/M cell cycle arrest in response to antimicrotubule agents. Oncogen 20: 6123-6131, 2001.

24. Lai D, Visser-Grieve S and Yang X: Tumour suppressor genes in chemotherapeutic drug response. Biosci Rep 32: 361-374, 2012.

25. Husain A, He G, Venkatraman ES and Spriggs DR: BRCA1 up-regulation is associated with repair-mediated resistance to cisdiamminedichloroplatinum(II). Cancer Res 58: 1120-1123, 1998.

26. Quinn JE, Kennedy RD, Mullan PB, Gilmore PM, Carty M, Johnston PG and Harkin DP: BRCA1 functions as a differential modulator of chemotherapy-induced apoptosis. Cancer Res 63: 6221-6228, 2003

27. Tassone P, Tagliaferri P, Perricelli A, Blotta S, Quaresima B, Martelli ML, Goel A, Barbieri V, Costanzo F, Boland CR and Venuta S: BRCA1 expression modulates chemosensitivity of BRCA1-defective HCC1937 human breast cancer cells. Br J Cancer 88: 1285-1291, 2003.

28. Stordal B and Davey R: A systematic review of genes involved in the inverse resistance relationship between cisplatin and paclitaxel chemotherapy: Role of BRCA1. Curr Cancer Drug Targets 9: 354-365, 2009.

29. Yang D, Khan S, Sun Y, Hess K, Shmulevich I, Sood AK and Zhang W: Association of BRCA1 and BRCA2 mutations with survival, chemotherapy sensitivity, and gene mutator phenotype in patients with ovarian cancer. JAMA 306: 1557-1565, 2011.

30. Chabalier C, Lamare C, Racca C, Privat M, Valette A and Larminat F: BRCA1 downregulation leads to premature inactivation of spindle checkpoint and confers paclitaxel resistance. Cell Cycle 5: 1001-1007, 2006

31. Papadaki C, Tsaroucha E, Kaklamanis L, Lagoudaki E, Trypaki M, Tryfonidis K, Mavroudis D, Stathopoulos E, Georgoulias V and Souglakos J: Correlation of BRCA1, TXR1 and TSP1 mRNA expression with treatment outcome to docetaxel-based first-line chemotherapy in patients with advanced/metastatic non-small-cell lung cancer. Br J Cancer 104: 316-323, 2011.

32. Thompson ME, Jensen RA, Obermiller PS, Page DL and Holt JT: Decreased expression of BRCA1 accelerates growth and is often present during sporadic breast cancer progression. Nat Genet 9: 444-450, 1995

33. Bièche I, Noguès $\mathrm{C}$ and Lidereau R: Overexpression of BRCA2 gene in sporadic breast tumours. Oncogene 18: 5232-5238, 1999.

34. Collins N, Wooster R and Stratton MR: Absence of methylation of $\mathrm{CpG}$ dinucleotides within the promoter of the breast cancer susceptibility gene BRCA2 in normal tissues and in breast and ovarian cancers. Br J Cancer 76: 1150-1156, 1997. 